Article

\title{
Effect of the Network Structure and Programming Temperature on the Shape-Memory Response of Thiol-Epoxy "Click" Systems
}

\author{
Alberto Belmonte ${ }^{1}$, Dailyn Guzmán ${ }^{2}$, Xavier Fernández-Francos ${ }^{3}$ and Silvia De la Flor ${ }^{1, *}$ \\ Received: 28 July 2015 ; Accepted: 21 October 2015 ; Published: 26 October 2015 \\ Academic Editor: Wei Min Huang \\ 1 Department of Mechanical Engineering, Universitat Rovira i Virgili, Av. Països Catalans 26, \\ 43007 Tarragona, Spain; albertofrancisco.belmonte@urv.cat \\ 2 Department of Analytical and Organic Chemistry, Universitat Rovira i Virgili, C/Marcel· lí Domingo s/n, \\ 43007 Tarragona, Spain; dailyn.guzman@estudiants.urv.cat \\ 3 Thermodynamics Laboratory, ETSEIB, Universitat Politècnica de Catalunya, Av. Diagonal 647, \\ 08028 Barcelona, Spain; xavier.fernandez@mmt.upc.edu \\ * Correspondence: silvia.delaflor@urv.net; Tel.: +34-97-755-8839; Fax: +34-97-755-9602
}

\begin{abstract}
This paper presents a new methodology to develop "thiol-epoxy" shape-memory polymers (SMPs) with enhanced mechanical properties in a simple and efficient manner via "click" chemistry by using thermal latent initiators. The shape-memory response (SMR), defined by the mechanical capabilities of the SMP (high ultimate strength and strain), the shape-fixation and the recovery of the original shape (shape-recovery), was analyzed on thiol-epoxy systems by varying the network structure and programming temperature. The glass transition temperature $\left(T_{\mathrm{g}}\right)$ and crosslinking density were modified using 3- or 4- functional thiol curing agents and different amounts of a rigid triglycidyl isocyanurate compound. The relationship between the thermo-mechanical properties, network structure and the SMR was evidenced by means of qualitative and quantitative analysis. The influence of the programming temperature $\left(T_{\text {prog }}\right)$ on the SMR was also analyzed in detail. The results demonstrate the possibility of tailoring SMPs with enhanced mechanical capabilities and excellent SMR, and intend to provide a better insight into the relationship between the network structure properties, programming temperature and the SMR of unconstrained (stress-free) systems; thus, making it easier to decide between different SMP and to define the operative parameters in the useful life.
\end{abstract}

Keywords: epoxy; thiol; shape-memory polymer; click chemistry

\section{Introduction}

Shape-memory polymers (SMPs) are materials that can change from a temporary shape to their original shape through an external stimulus. The original shape is given by the curing process and it is permanent while the temporary shape is imposed by a programming process, which depends on the physical nature of the shape-memory polymer (SMP) [1-4]. The most common type are the thermo-responsive SMPs [5]. The efficiency of a SMP is defined by the shape-memory response (SMR), which includes the mechanical capabilities (high ultimate strength and strain), good fixation and retention of the temporary shape and well-controlled shape-recovery process. Shape-memory thermosets are recently the focus of several researchers due to the higher strength, larger durability, better retention of the temporary shape and faster recovery of the original shape than those SMPs based on thermoplastics. Specifically, epoxy-based SMPs are interesting because of their excellent mechanical properties, electrical insulation and high thermal stability, being potentially 
interesting in structural applications [3,6]. Nevertheless, the inherent rigidity of common epoxy resins, their low strain and stress at break, narrows their application range.

Many researchers employ curing agents characterized by flexible and long aliphatic chains to overcome the deformability limitations. Wei et al. [7] enhanced the segmental mobility by introducing a long flexible chain of poly(propylene glycol) diglycidyl ether (PPGDGE) in epoxy-amine formulations. Rousseau et al. [8] used curing agents of different nature (aliphatic-based, propylene oxide (PO)-based, ethylene oxide (EO)-based, PO/EO) on a DGEBA (epoxy resin) and studied the influence of the network structure on the ultimate strain and the impact on the shape-recovery. The results indicated that by carefully varying the network structure it was possible to increase the tensile elongation while maintaining high values of glass transition temperature $\left(T_{\mathrm{g}}\right)$ and obtaining excellent shape-recovery performances. On the other hand, another approach to enhance the ultimate strain based on the effect of the programming temperature $\left(T_{\text {prog }}\right)$ was investigated by Yakacki et al. [9] working with acrylates and Rousseau et al. [10] using epoxy-based systems. The results demonstrated an improvement of the strain at break of three- to five-fold, when deforming at a temperature slightly below the $T_{\mathrm{g}}$, corresponding to the onset point of the network relaxation process (measured by dynamic-mechanical analyses). Recently, Zheng et al. [11] presented a high strain two component epoxy-amine (up to $210 \%$ of strain at break when deforming at the onset temperature) with tailorable $T_{\mathrm{g}}$ and excellent shape-fixity and shape-recovery performances.

Nevertheless, while the ultimate strain is highly enhanced by varying the network structure, both the ultimate strength and the shape-recovery process are affected by these changes. In structural and aerospace applications [12,13] the capability to perform a mechanical work and the control of the shape-recovery process are highly demanded to properly tailor materials for specific conditions. However, one of the major drawbacks is to fulfil both, high ultimate strength and strain. Moreover, the enhancement of the strain limits leads to uncontrolled modifications of the shape-recovery process. To this end, very few works have focused on the study of the relation between the network structure and, either the strength or the shape-recovery process. Williams et al. [14] improved the tensile strain of an epoxy-based system and reported a great strength by combining chemical and physical crosslinking through a long aliphatic chain (n-dodecylamine) and a compact rigid structure (m-xylylenediamine). Our group developed hyperbranched poly(ethyleneimine)-modified epoxy SMPs with enhanced ultimate strength (up to $12 \mathrm{MPa}$ of stress at break), maintaining high ultimate strain [15]. On the other hand, Yakacki et al. [16,17] studied the dependence of the shape-recovery process on the network structure in constrained and unconstrained (stress-free) conditions.

The results evidenced the relationship between the network relaxation dynamics and the unconstrained (stress-free) recovery process, and the dependence on the crosslinking density for the constrained ones. Chen et al. [18] evidenced the influence of the network relaxation dynamics in unconstrained recovery processes by means of numerical simulations. However, the enhanced ultimate strength and strain reported are not sufficiently high, and the knowledge of the network structure role on the shape-recovery process is not yet well-defined. More efforts to better understand the relation of the network structure properties with the shape-recovery process and ultimate mechanical properties are required to advance in the development of smart materials.

The so-called click chemistry is a new generation of reactions based on efficiency, versatility and selectivity [19-21]. Among the different "click" mechanisms, the thiol-epoxy systems [22] are especially interesting due to the formation of hydroxyl and thioether groups in a single step during the polymerization process, which can be further transformed into other polymeric structures [23,24]. Tertiary amines are commonly used as base catalysts in thiol-epoxy formulations, but they are usually too reactive, making it hard to control the reaction and shortening their pot-life. It was recently shown $[25,26]$ that it is possible to increase the pot life of thiol-epoxy formulations by means of polymer-encapsulated amines or thermally stable aromatic-aliphatic ureas, being the former the most effective way. Thus, it is possible to prepare formulations, store them safely before application, 
and process them at temperatures high enough to quickly release the amine catalyst and produce a completely cured material in a short period of time.

Over the last few years, some reports have been published on the use of the "click" concept to synthesize SMPs. Shandas et al. [27] used UV-induced thiol-ene polymerization to develop SMPs with a wide range of mechanical and thermo-mechanical properties with excellent SMR. Afterwards, Sunitha et al. [28] and McBride et al. [29] synthesized SMPs based on azyde-alkine-CuAAC "click" chemistry with high shape-recovery and shape-fixation performances. To the best of our knowledge, though, the "click" chemistry via nucleophilic attack to strained heterocycles (i.e., the thiol-epoxy mechanism), using thermal latent initiators, has not been yet investigated on the development of SMPs.

In this paper, we combine the advantages of using "click" thiol-epoxy reaction with latent catalysis to produce SMPs with enhanced mechanical properties (high ultimate strength and strain) in a simple and efficient manner. This study expects to provide, by means of a detailed thermal and mechanical characterization of these materials, a better understanding on the relationship between the network structure and thermo-mechanical properties with the SMR, and to establish sound criteria for material choice depending on the expected application or certain operation conditions. In this sense, it is expected to clarify as much as possible the parameters one should consider depending on the desired applications. On the other hand, by varying the programming temperature, it is intended to link both the enhancement on the mechanical properties $[9,10]$ with the effect on the SMR. For this purpose, in this work, (3- and 4- functional) thiol components have been used as curing agents for a commercial diglycidyl ether of bisphenol A (DGEBA) via "click" chemistry using encapsulated amines as latent initiators. In addition, different amounts of triglycidyl isocyanurate (iso) have been used as network structure modifiers in order to increase the $T_{\mathrm{g}}$ and the crosslinking density of the material. The SMR has been analyzed using different programming temperatures (below, at and above the $T_{\mathrm{g}}$ ), and has been related to the network structure changes induced by the addition of isocyanurate and the use of thiol components of different functionality.

\section{Experimental Section}

\subsection{Materials}

A commercial epoxy resin, Diglycidyl ether of bisphenol A (DGEBA, GY240, Huntsman, Everberg, Belgium) with a molecular weight per epoxy equivalent unit of 182 g/equiv was used as the main epoxy resin. Pentaerythritol tetrakis (3-mercaptopropionate) (4thiol), with a molecular weight per thiol equivalent unit of $122.17 \mathrm{~g}$ /equiv (Sigma-Aldrich, St. Louis, MO, USA) and trimethylolpropane tris(3-mercaptopropionate) (3thiol), with a molecular weight per thiol equivalent unit of $132.85 \mathrm{~g}$ /equiv (Sigma-Aldrich, St. Louis, MO, USA) were used separately as crosslinking agents. In addition, a tri(2,3-epoxypropyl)isocianurate (iso), with a molecular weight per epoxy equivalent unit of $99.09 \mathrm{~g}$ /equiv (Sigma-Aldrich, St. Louis, MO, USA) was used as a modifier in different weight proportions: $10 \%, 20 \%, 30 \%$ and $40 \%$ (i.e., 10:90 wt \% ISO:DGEBA), maintaining a stoichiometric proportion of thiol and epoxy groups (epoxy:thiol ratio equal to 1:1). An encapsulated imidazole (LC80, AC Catalysts) was used as a latent initiator in a proportion of $0.5 \mathrm{phr}$ (parts of catalyst for hundred parts of epoxy resin). The reagents were used as received, without further purification.

The formulations were prepared by manually stirring the components in a glass vial and carefully pouring the mixtures in an open teflon mold. The curing process was carried out in an oven, one hour at $120{ }^{\circ} \mathrm{C}$ followed by one hour at $150{ }^{\circ} \mathrm{C}$ to allow the completion of the process. Scheme 1 shows the expected network for the mixtures without iso and Scheme 2 the expected changes introduced by the iso (the crosslinking points have been highlighted). 

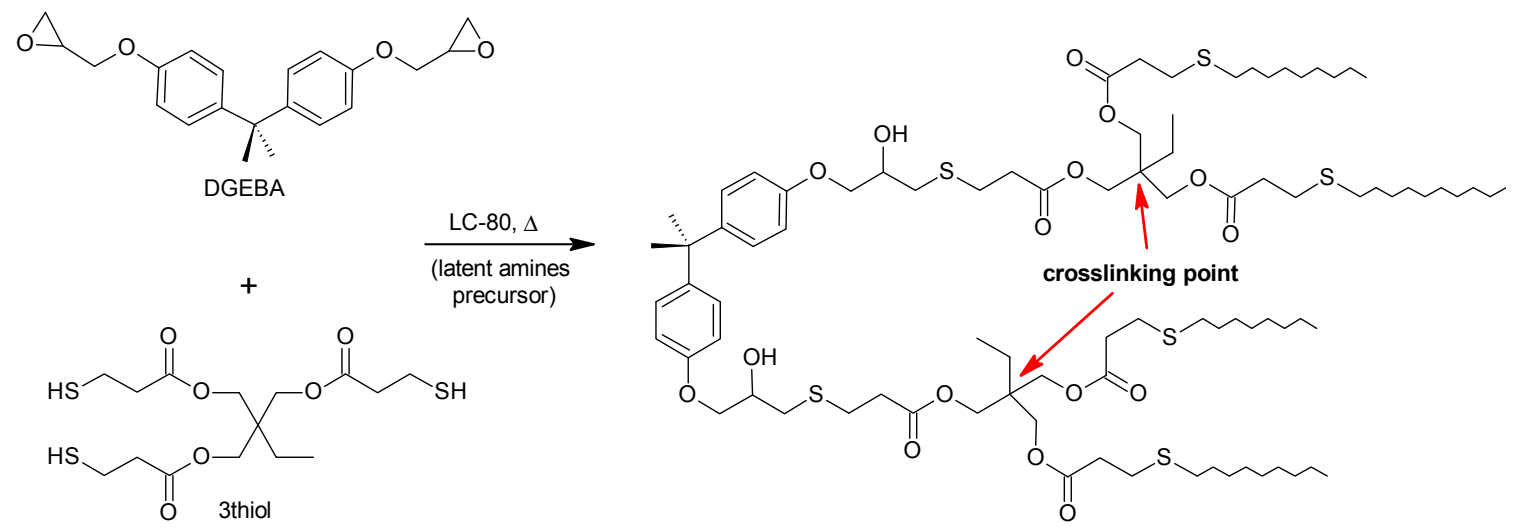

Scheme 1. Reaction scheme and expected network structure of the mixture containing 3thiol as curing agent, DGEBA as epoxy resin and LC-80 as initiator (3thiol-DGEBA-LC80) formulation.

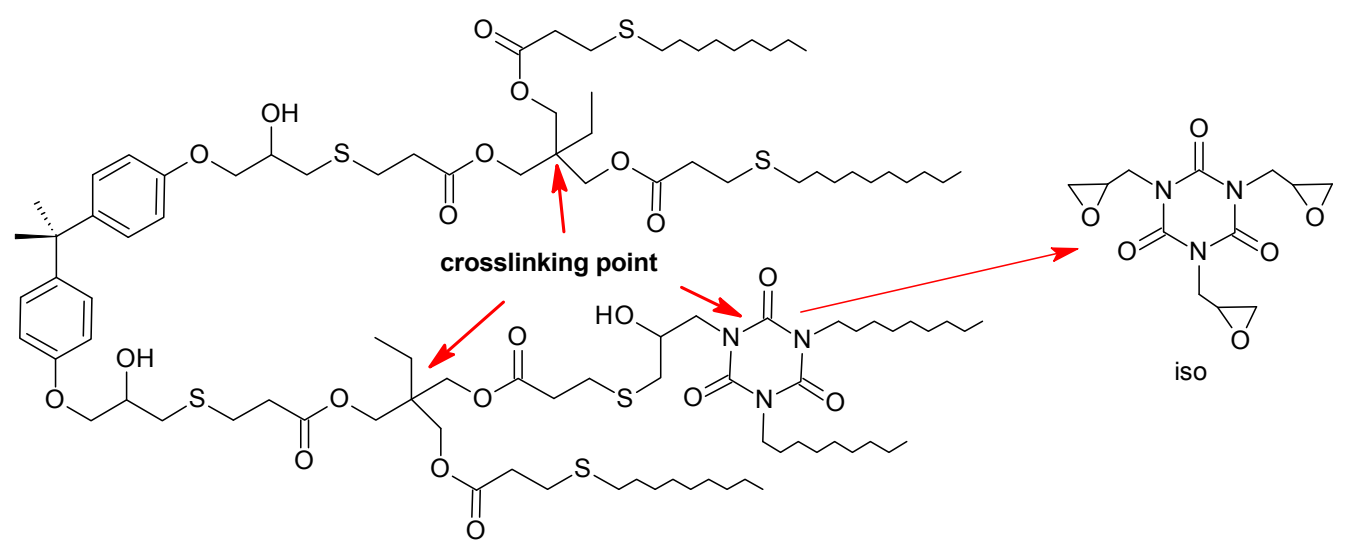

Scheme 2. Expected network structure of the 3thiol-DGEBA-LC80 modified with the (iso) component.

The composition of the different formulations considered is detailed in Table 1.

Table 1. Composition of the different formulations of study.

\begin{tabular}{ccccc}
\hline Formulation & DGEBA (wt \%) & Thiol (wt \%) & ISO (wt \%) & LC80 (wt \%) \\
\hline 3thiol-NEAT & 57.64 & 42.07 & 0.00 & 0.29 \\
3thiol-(10\%)iso & 50.11 & 44.04 & 5.57 & 0.28 \\
3thiol-(20\%)iso & 43.08 & 45.88 & 10.77 & 0.27 \\
3thiol-(30\%)iso & 36.49 & 47.61 & 15.64 & 0.26 \\
3thiol-(40\%)iso & 30.31 & 49.22 & 20.21 & 0.25 \\
4thiol-NEAT & 59.66 & 40.04 & 0.00 & 0.30 \\
4thiol-(10\%)iso & 51.95 & 41.99 & 5.77 & 0.29 \\
4thiol-(20\%)iso & 44.73 & 43.81 & 11.18 & 0.28 \\
4thiol-(30\%)iso & 37.95 & 45.52 & 16.26 & 0.27 \\
4thiol-(40\%)iso & 31.56 & 47.13 & 21.04 & 0.26 \\
\hline
\end{tabular}

\subsection{Network Structure and Thermo-Mechanical Properties}

The network structure and thermo-mechanical properties of the different materials were studied by thermo dynamic-mechanical analyses using a DMA Q800 (TA instrument) equipped with a Single-Cantilever $(10 \mathrm{~mm})$ clamp. The samples were thoroughly polished until a prismatic rectangular shape $\left(\approx 20 \times 7.5 \times 1.8 \mathrm{~mm}^{3}\right)$ was obtained. The samples were analyzed at $1 \mathrm{~Hz}$ with oscillation amplitude of $10 \mu \mathrm{m}$ at a heating rate of $3^{\circ} \mathrm{C} / \mathrm{min}$. Figure 1 shows a typical representation 
of the curves obtained by DMA. The $T_{\mathrm{g}}$ was determined by the peak of the $\tan \delta$ curve, both, the modulus at room temperature $\left(E_{\mathrm{g}}{ }^{\prime}\right)$ and above the glass transition $\left(E_{\mathrm{r}}{ }^{\prime}\right)$, were determined directly from the storage modulus curve $\left(E^{\prime}\right)$. The onset point $\left(T_{\mathrm{g}}{ }^{\prime}\right)$ was determined as the intersection of the lines corresponding to the plateau in the glassy state and the modulus fall. In addition, the width of the $\tan \delta$ curve at the half-height (FWHM) and the $\tan \delta$ peak have been determined as shown in Figure 1.

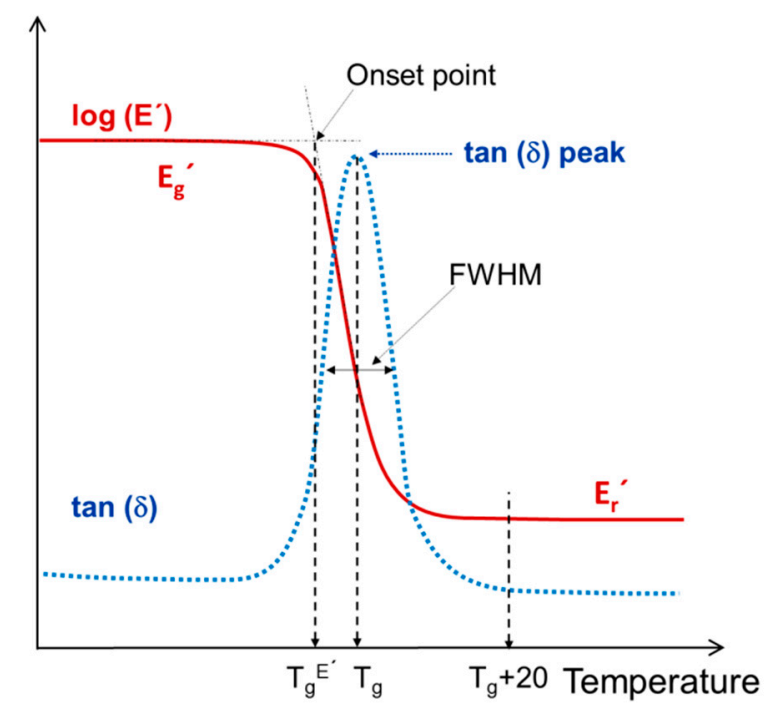

Figure 1. Schematic representation of the relevant parameters obtained from DMA analysis: storage modulus $\left(E^{\prime}\right)$ and $\tan \delta$ curve for a typical thermoset. The parameters of interest have been pointed out.

According to the Affine model for ideal rubbers, the relaxed modulus $E_{\mathrm{r}}{ }^{\prime}$ at low strain rates is related to the strand density of the crosslinked network by Equation (1).

$$
E_{r}^{\prime}=3 \cdot R \cdot T \cdot \rho \cdot v_{e}
$$

where $R$ is the universal gas constant, $T$ is the temperature at which the modulus $E_{\mathrm{r}}{ }^{\prime}$ is calculated, $\rho$ is the density of the material at the temperature $T$ and $v_{\mathrm{e}}$ is the network strand density. Usually, the network strand density $v_{\mathrm{e}}$ is considered to depend on the crosslink density and functionality as:

$$
v_{e}=\sum_{f \geqslant 3}\left(n_{f} \cdot \frac{f}{2}\right)
$$

where $n_{f}$ is the density of crosslinking junctions with functionality $f$. However, it has been shown that the mobility of the network strands and their deformation is further affected by the functionality of the crosslinking points [30] due to the fluctuation of crosslinks in the network, so that modifications to the ideal expression have been proposed such as [31]:

$$
v_{e}=\sum_{f \geqslant 3}\left(n_{f} \cdot \frac{f-2}{2}\right)
$$

For the correct evaluation of this parameter, one has to take into account the composition of the formulation and that, in the fully cured materials, 3thiol and iso contribute with trifunctional crosslinks, and 4thiol with tetrafunctional crosslinks.

Other non-idealities should have an influence in the value of $E_{\mathrm{r}}{ }^{\prime}$, such as the presence of permanent physical entanglements [31] or the non-Gaussian deformation of the network strands [32]. 
Lesser and Crawford [33] studied the dependence of the glass transition temperature on the crosslinking density and the crosslinking functionality, and proposed the following modification of the classical free-volume based relationship taking into account the effect of crosslink fluctuation, as:

$$
T_{g, x}=T_{g \infty}+\frac{2 \cdot\left(f_{\text {ave }}-2\right)}{f_{\text {ave }}} \cdot \frac{\zeta}{M_{c}}
$$

where $T_{\mathrm{g}, x}$ is the glass transition temperature at a conversion $x, f_{\text {ave }}$ is the average crosslink functionality, $\zeta$ is proportional to the molecular weight of the unreacted resin and to the ratio of incremental free volume contributions from the resin and the curing agent, and $M_{\mathrm{c}}$ is the average mass between crosslinks. This expression can be conveniently rearranged and adapted for the present case of comparison between similar materials with differing crosslinking density and functionality. It can be shown that the $T_{\mathrm{g}}$ is approximately proportional to the an effective crosslinking density, in a similar way to the Fox-Loshaek equation [34] yielding:

$$
T_{g}=a+b \cdot v_{e}
$$

where $\mathrm{a}$ and $\mathrm{b}$ are constants and $v_{\mathrm{e}}$ is calculated using expression (3), taking into account crosslink fluctuation and functionality. Other expressions have been proposed to account for other non-idealities $[35,36]$ but they are not considered for simplicity purposes.

\subsection{Mechanical Characterization}

The mechanical response was analyzed through stress-strain experiments using the DMA Q800 (TA instrument, New Castle, DE, USA) equipped with a Tension-Film clamp in Force-controlled mode at a range of temperatures (from $T_{\text {room }}$ to $T_{\mathrm{g}}+20$ ). Dog-bone shaped samples were polished thoroughly with sandpaper in order to obtain controlled size samples (length $\times$ thickness $\times$ width $\approx 15 \times 0.5 \times 1.4 \mathrm{~mm}^{3}$, see Figure 2) and were annealed during $10 \mathrm{~min}$ at $120{ }^{\circ} \mathrm{C}$ in an oven before testing. The samples were mounted and carefully held between the grips of the clamp to ensure an initial testing length of 10-11 $\mathrm{mm}$. The pressure applied in both grips was sufficiently low to avoid cutting the sample, and sufficiently high to avoid slipping. The experiments were carried out at $3 \mathrm{~N} / \mathrm{min}$. The stress and strain at break $\left(\sigma_{\mathrm{b}}\right.$ and $\varepsilon_{\mathrm{b}}$ respectively) were determined as the failure point from the curves obtained.
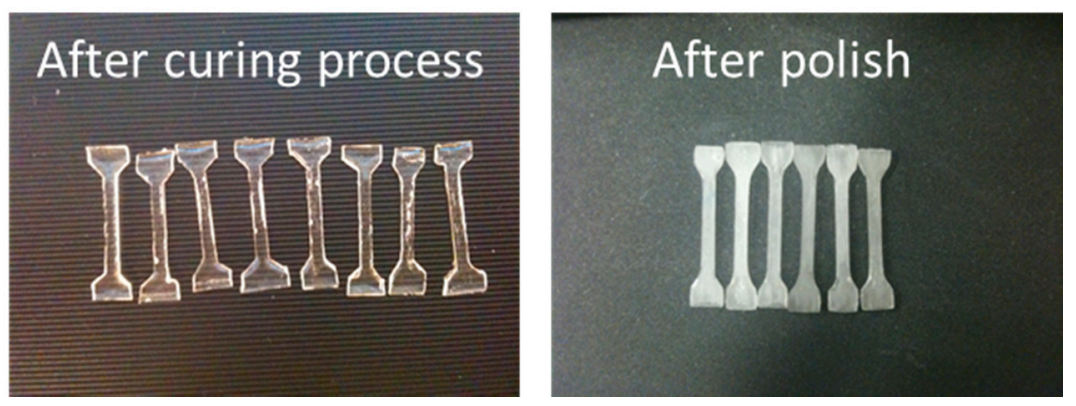

Figure 2. Dog-bone shaped samples preparation process.

\subsection{Shape-Memory Response (SMR)}

The SMR of all the formulations was investigated through a visual methodology (qualitative study) for comparison purposes and as a means of choosing the best candidates for further analyzing the effect of the programming temperature in the SMR (quantitative study). 


\subsubsection{Qualitative Study}

The SMR was analyzed using a visual methodology to monitor isothermal-recovery processes. Prismatic rectangular samples of $40 \times 8 \times 2.5 \mathrm{~mm}^{3}$ (length $\times$ width $\times$ thickness) were polished to flat parallel surfaces. The programming process was performed following the next steps: the sample was heated up to the programming temperature $\left(T_{\mathrm{prog}}\right)$ stipulated as its $T_{\mathrm{g}}$ to make possible the comparison among the different formulations under study, and then deformed to a U-shape using the bending device shown in Figure 3a. The device and the sample were rapidly cooled down with cold water while maintaining the force applied. The sample was unloaded and was placed in an oven at the isothermal recovery temperature $\left(T_{\text {rec }}\right)$ corresponding to its $T_{\mathrm{g}}$ (following the same line of reasoning as for the $T_{\text {prog }}$ ) as shown in Figure $3 \mathrm{~b}$. The process was recorded using a high resolution camera and further analyzed frame by frame (one frame per second of the video), measuring the angles as shown in Figure $3 \mathrm{~b}$ and applying Equation (6) on each frame. The time needed to recover from the $15 \%$ to the $85 \%$ of the original shape $\left(t_{\mathrm{sr}}\right)$ was determined using the Equation (7) (the beginning and the end of the process were neglected to avoid possible experimental errors since it is a visual methodology).

(a)

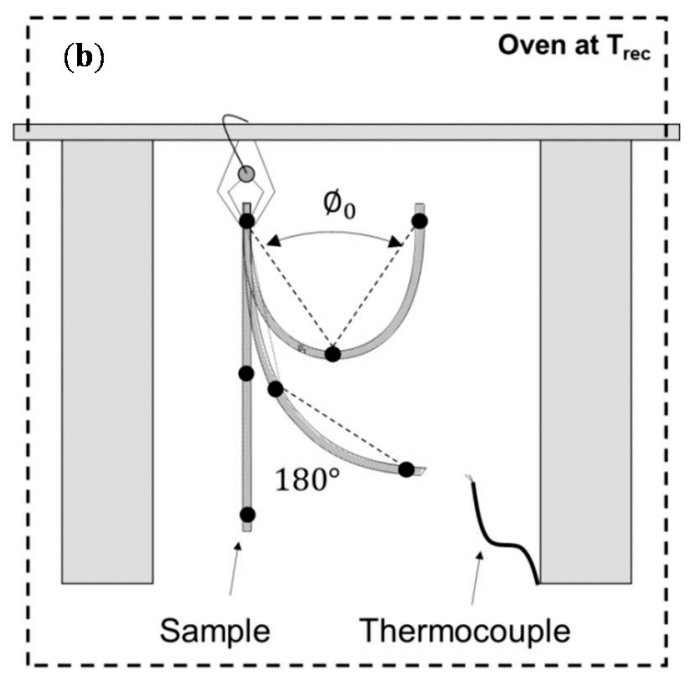

Figure 3. Schematic representation of the bending device; (a) and the shape-recovery scenario; (b) for the isothermal-recovery experiments.

$$
\begin{gathered}
(\% S R)_{\Phi}=\frac{\Delta \Phi_{t}}{180^{\circ}-\Phi_{0}} \cdot 100 \\
t_{s r}=t_{(\% S R)_{85}}-t_{(\% S R)_{15}}
\end{gathered}
$$

where $\% S R$ is the shape-recovered in percentage, $\Phi_{0}$ is the initial angle and $\Delta \Phi_{t}$ is the difference between the angle at a time $t, \Phi_{t}$, and $\Phi_{0}$. $t_{\mathrm{sr}}$ is the shape-recovery time.

\subsubsection{Quantitative Study}

In the quantitative study, the SMR was analyzed through a customized experimental method using the DMA Q800 (TA Instrument) equipped with the Tension-Film clamp. The samples were prepared in the same way as for their mechanical characterization (see Figure 2). The experiments were performed following the steps shown in Figure 4 three $T_{\text {prog }}$ were chosen: $T_{\mathrm{g}} E^{\prime}, T_{\mathrm{g}}$ and $T_{\mathrm{g}}$ +20 , to quantify the SMR at the optimal mechanical point $\left(T_{\mathrm{g}}{ }^{\prime}\right)[9,10]$ and along the glass transition process $\left(T_{\mathrm{g}}\right.$ and $\left.T_{\mathrm{g}}+20\right)$. The samples were heated up to $T_{\mathrm{prog}}$ and held during $5 \mathrm{~min}$ at this temperature to ensure thermal equilibrium (point 1 in Figure 4). A uniaxial tensile deformation at a constant force rate of $1 \mathrm{~N} / \mathrm{min}$ was applied until the $75 \%$ of $\varepsilon_{\mathrm{b}}\left(\varepsilon_{\mathrm{D}}\right)$ was reached (line a to point 2 in 
Figure 4). This limit of $75 \%$ of $\varepsilon_{\mathrm{D}}$ was used in order to make comparisons between the formulations regardless of their different network structure and mechanical properties, also depending on $T_{\text {prog, }}$, as well as to quantify the SMR near the maximum elongation allowed. Once $\varepsilon_{\mathrm{D}}$ was reached, the force applied was held constant while rapidly cooling to setting temperature ( $\left.T_{\mathrm{s}}\right)$ (line $\mathrm{b}$ to point 3 ). Subsequently, the force applied was released at the same force rate of $1 \mathrm{~N} / \mathrm{min}$ (line c to point 4). Afterwards, a heating rate of $3{ }^{\circ} \mathrm{C} / \mathrm{min}$ was imposed until the original shape was recovered (line $\mathrm{d}$ to point 5 ). All the other experimental conditions and parameters remained unchanged.

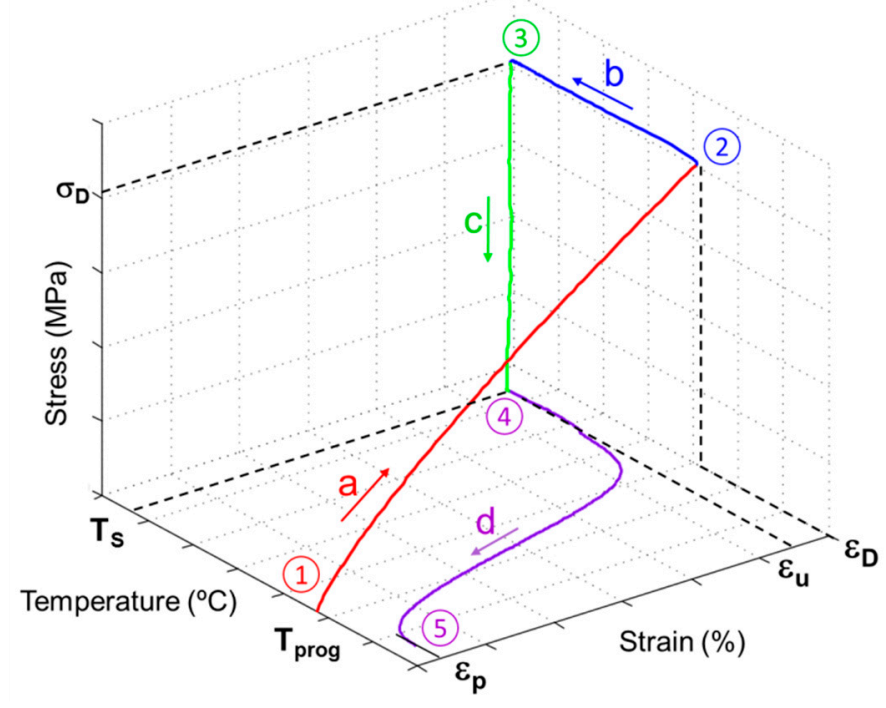

Figure 4. Thermo-responsive SMPs; 3D representation of the programing process.

The SMR was analyzed as the average of the results through three consecutive cycles (it was not appreciated any worsening of the SMR during the cycling until the sample broke). The capability of the material to recover its original shape was determined by the shape-recovery ratio $\left(R_{\mathrm{r}}\right)$, using the Equation (8) and the capability to retain the imposed shape (temporary shape) was determined by the fixation-ratio $\left(R_{f}\right)$, using Equation (9).

$$
\begin{gathered}
\mathrm{R}_{\mathrm{r}}(\%)=\frac{\varepsilon_{\mathrm{D}}-\varepsilon_{\mathrm{p}}}{\varepsilon_{\mathrm{D}}} \cdot 100 \\
\mathrm{R}_{\mathrm{f}}(\%)=\frac{\varepsilon_{\mathrm{u}}}{\varepsilon_{\mathrm{D}}} \cdot 100
\end{gathered}
$$

where $\varepsilon_{\mathrm{D}}$ is the deformation reached after loading, $\varepsilon_{\mathfrak{u}}$ is the deformation after unloading and $\varepsilon_{\mathrm{p}}$ is the permanent strain after the shape-recovery. All these parameters are represented in Figure 4.

The shape-recovery rate $\left(V_{\mathrm{r}}\right)$ was calculated using the Equations (10) and (11), enclosing the whole process (from $1 \%$ to $100 \%$ of the original shape recovered) and avoiding the early and final stages (from $15 \%$ to $85 \%$ ).

$$
\begin{gathered}
\% \mathrm{SR}=100-\frac{\varepsilon-\varepsilon_{\mathrm{p}}}{\varepsilon_{\mathrm{u}}-\varepsilon_{\mathrm{p}}} \cdot 100 \\
\mathrm{~V}_{\mathrm{r}}\left(\% /{ }^{\circ} \mathrm{C}\right)=\frac{\Delta \% \mathrm{SR}}{\Delta \mathrm{T}_{\Delta \% \mathrm{SR}}}
\end{gathered}
$$

where $\% S R$ is the percentage of original shape recovered normalized to the permanent strain $\left(\varepsilon_{\mathrm{p}}\right)$, $\Delta \% S R$ is the range tested $(\% S R=1 \%-100 \%$ and $15 \%-85 \%)$ and $\Delta T_{\Delta \% S R}$ is the temperature increment corresponding to the $\Delta \% S R$. 


\section{Results and Discussion}

\subsection{Thermo-Mechanical and Network Structure Properties}

The thermo-mechanical and network structure properties were analyzed by dynamic-mechanical analyses. The results for the 3thiol and 4thiol systems are shown in Figures 5 and 6 and some characteristic parameters of the network relaxation process (see Figure 1) are summarized in Table 2 .

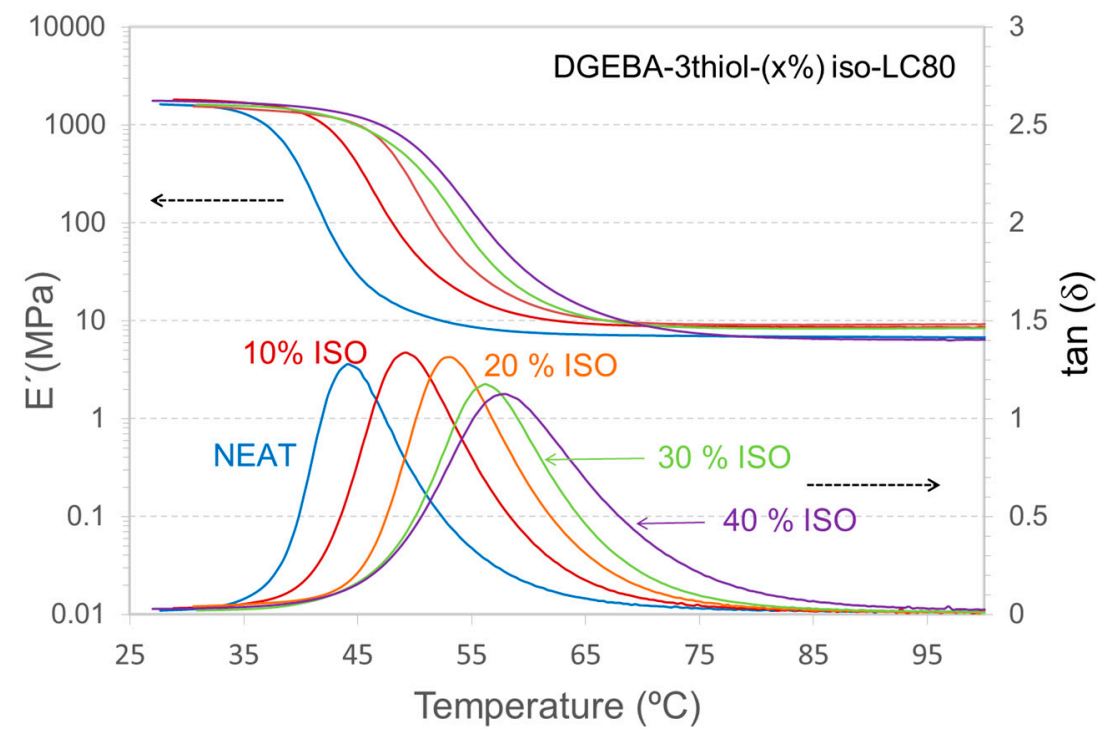

Figure 5. Dynamic-mechanical analyses for the (3thiol) different formulations.

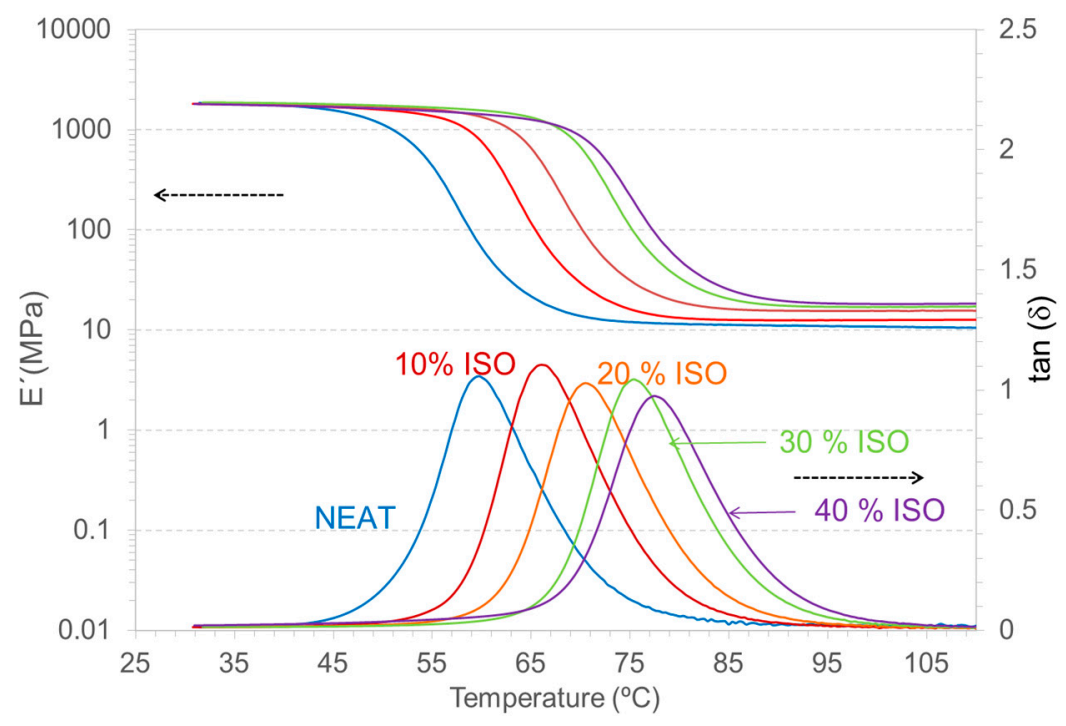

Figure 6. Dynamic-mechanical analyses for the (4thiol) different formulations.

In general, the formulations with 3thiol have lower $T_{\mathrm{g}}$ than those with 4thiol because of the reduction of free volume and hindrance of the molecular motion caused by the presence of crosslink junctions [36], which becomes more relevant with increasing crosslink functionality [33], as seen for other shape-memory materials $[37,38]$. On the other hand, adding the iso compound to the different systems tend to increase the $T_{\mathrm{g}}$. According to the expected network of the Scheme 2, the iso component acts as a 3-functional crosslinking point, increasing the functionality of the system, thus, 
creating a more hindered network. Nevertheless, the $T_{\mathrm{g}}$ increment tends to become less relevant especially above an iso content up to 30\% for formulations containing 3thiol. Figure 7 shows a good correlation between the $T_{\mathrm{g}}$ and the effective strand density $v_{\mathrm{e}}$ (calculated taking into account crosslink functionality and fluctuation, using Equation (3)), showing a fairly linear trend as predicted by Equation (5). However, some non-idealities appear for both 3thiol and 4thiol formulations with increasing iso content and, consequently, $v_{\mathrm{e}}$. It must be taken into account that the increase in the content of iso also changes the type of network structure, introducing crosslinks with a non-negligible mass, and the size and rigidity of the network strands [25].
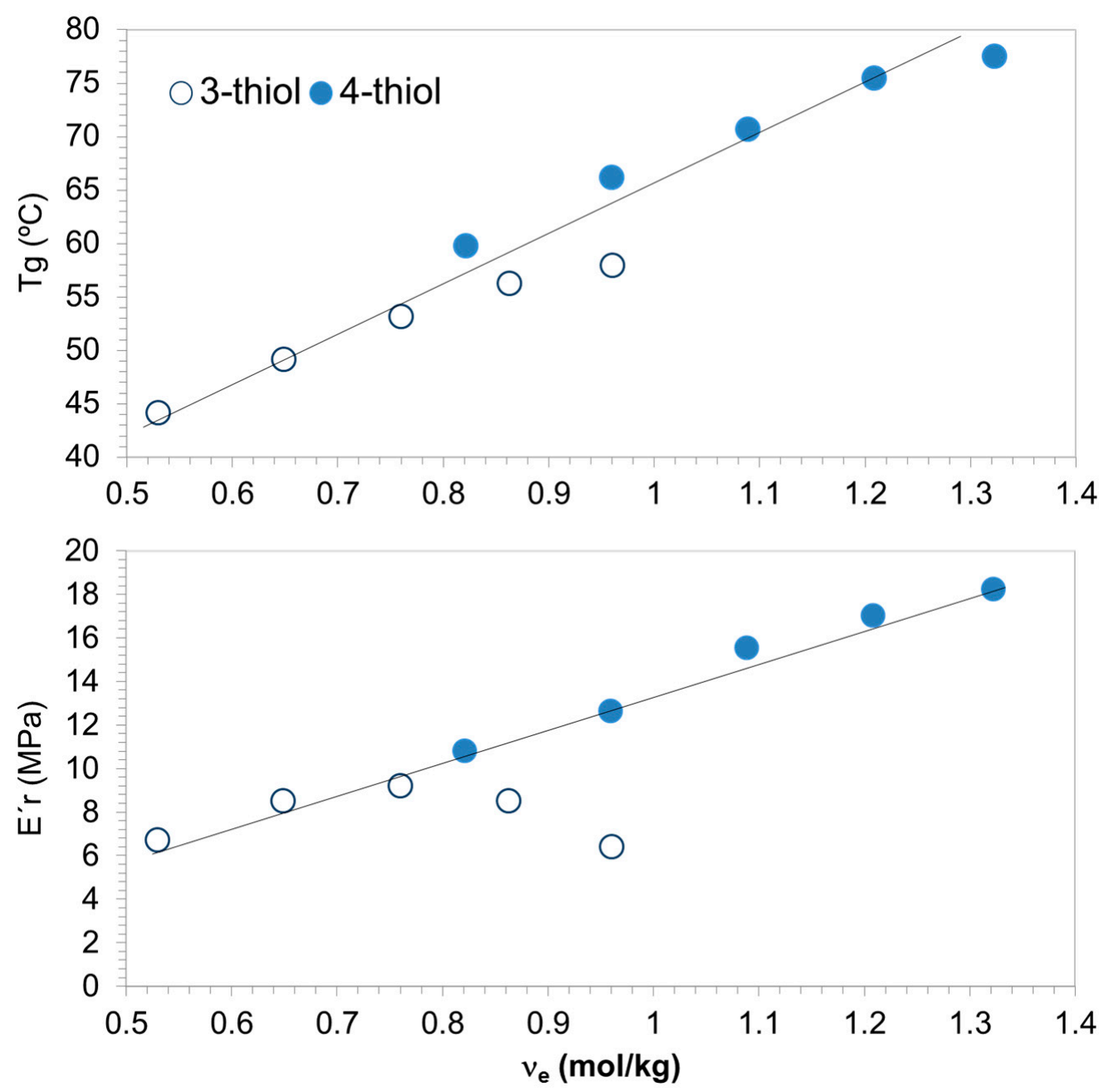

Figure 7. $\left(T_{\mathrm{g}}\right)$ and $\left(E_{\mathrm{r}}{ }^{\prime}\right)$ with respect to the effective strand density $\left(v_{\mathrm{e}}\right)$ corresponding to each $\%$ of iso content.

FWHM and $\tan \delta$ peak values are characteristics of the relaxation and can be related to the crosslinking density and the network homogeneity of the material. It is commonly observed that the relaxation peaks broaden and decrease its intensity with increasing crosslinking density [15] a phenomenon that is inherently related to the increase in crosslinking density and $T_{\mathrm{g}}$ [34]. Although the trend is not well defined, because of the discrete increase in crosslinking density, the same is observed in the present case. The effect of iso on the shape of the relaxation in 4thiol systems is very limited in comparison with 3thiol and, in fact, the broadening of the relaxation when $40 \%$ of iso is used with 3thiol is too large and may have a detrimental effect on the SMR of the material. 
Table 2. Network structure and thermo-mechanical properties of the different materials of study.

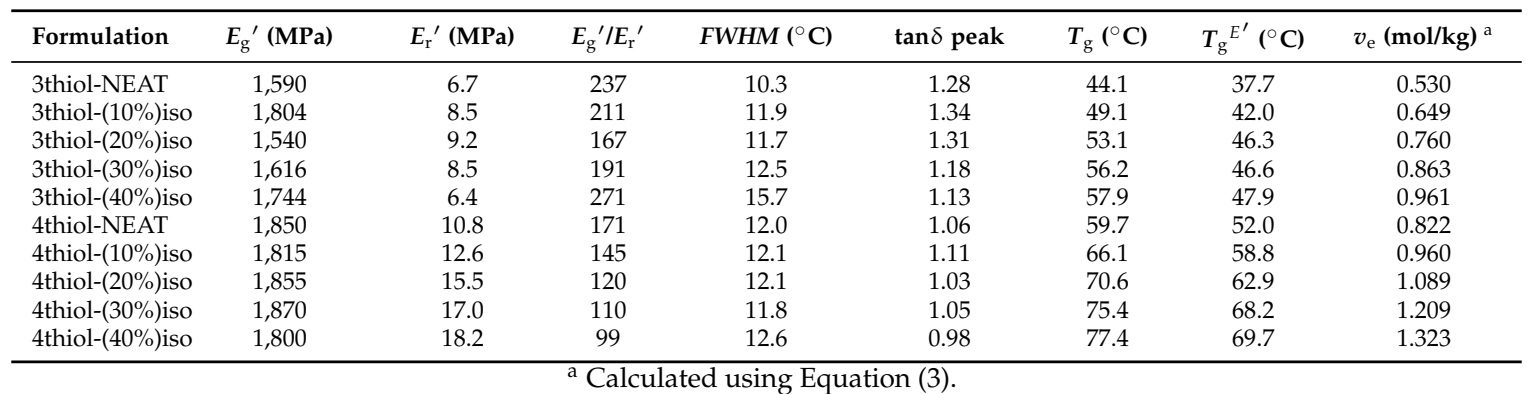

The effective strand density $v_{\mathrm{e}}$ (calculated taking into account crosslink functionality and fluctuation, using Equation (3)) shows an increasing trend with the addition of iso and with the increase in the thiol functionality from 3thiol to 4thiol, as expected. The measured values of the relaxed modulus $E_{\mathrm{r}}{ }^{\prime}$ have a very good agreement with this trend except 3thiol formulations with $30 \%$ and $40 \%$ of iso, that show decreasing values of $E_{\mathrm{r}}{ }^{\prime}$. Such discrepancies are in line with the non-idealities observed in the $T_{\mathrm{g}}$ and the broadening of the relaxation peak in 3thiol formulations with higher iso content.

Differences between 3thiol and 4thiol formulations may be consequence of the different structure of both crosslinking agents. Setting aside the different functionality, 3thiol has a pendant ethyl group that may produce a certain distortion in the network structure and the network relaxation dynamics, thus affecting the whole of the measured parameters. In addition, one must consider that the introduction of iso produces not only an increase in crosslinking density but also a significant change in the network structure. Such considerations fall out the scope of the simple theoretical expressions used in this work. Furthermore, it is possible that this also results from a certain incompatibility between iso and 3thiol or a difference in the reactivity of the epoxy groups of iso and DGEBA, leading to an inhomogeneous distribution of the different types of network strands and crosslinking points.

\subsection{SMR Qualitative Study: Comparison with Thermo-Mechanical Properties and Network Structure}

From the previous thermo-mechanical analysis, a series of general considerations can be made in terms of the SMR of the different materials. The capability of a material to show shape-recovery is usually quantified by the $E_{\mathrm{g}}{ }^{\prime} / E_{\mathrm{r}}{ }^{\prime}$ ratio [15]. Table 2 shows that the $E_{\mathrm{g}}{ }^{\prime} / E_{\mathrm{r}}{ }^{\prime}$ ratio is over 2 orders of magnitude or above for all the formulations, a high enough value. The drop of the modulus from $E_{\mathrm{g}}{ }^{\prime}$ to $E_{\mathrm{r}}{ }^{\prime}$ during the network relaxation is steep enough to expect high rates during the shape-recovery process (see Figures 5 and 6). In addition, there is a plateau zone of $E_{\mathrm{g}}{ }^{\prime}$ at the $T_{\mathrm{s}}$ (temperature at which the temporary shape is fixed) sufficiently away from the modulus drop zone to avoid premature shape-recovery and consequently allow good shape-fixation. Overall, the shape of the network relaxation process, represented by the $\tan \delta$ curve, is well-defined along the glass transition (no noise is noticed) and it is similar for all the formulations, expecting a similar SMR.

In the qualitative study, the SMR has been analyzed through the $t_{\mathrm{sr}}$ parameter (see Equation (7)), since no losing of the temporary shape was visually appreciated after cooling and releasing the stress applied to the sample. In addition, the programmed samples showed good retention of the temporary shape during the 5-10 min of holding time at room temperature before the shape-recovery was triggered inside the oven. Moreover, at the end of the process, the recovery of the original shape was quantitative $\% S R \approx 100 \%$ (Equation (8)), leaving no appreciable permanent strain.

As it can be seen in Figure 8, overall the $t_{\mathrm{sr}}$ is excellent for all the formulations as expected from the $E_{\mathrm{g}}{ }^{\prime} / E_{\mathrm{r}}{ }^{\prime}$ ratio and the sharp relaxation. The materials are capable of recovering from the $15 \%$ to the $85 \%$ of their original shape in less than $14 \mathrm{~s}$ when heated on air (note that, in many applications such as security devices, the heating process is on air through isothermal conditions). The NEAT 
formulations show a similar response, about $12 \mathrm{~s}$ of $t_{\mathrm{sr}}$, while the addition of $10 \%$ of iso accelerates the shape-recovery process for both systems ( $t_{\mathrm{sr}}$ falls to $\left.10-9 \mathrm{~s}\right)$. In contrast, increasing the amount of iso from $10 \%$ to $40 \%$ slows down the process in the case of the 3thiol formulations $\left(t_{\text {sr }}\right.$ increases from $10 \mathrm{~s}$ at $10 \%$ of iso up to $13 \mathrm{~s}$ at $40 \%$ of iso), while for the 4thiol ones it remains almost constant. Figure 8 compares the $t_{\mathrm{sr}}$ along with the $\tan \delta$ peak (a) and FWHM (b) values in order to relate the SMR with the network structure. As it can be seen, $t_{\text {sr }}$ decreases when the tan $\delta$ peak increases and when FWHM decreases. These results point at a strong relationship between the sharpness of the relaxation process and the rate of the shape-recovery process. Materials with a more heterogeneous network structure and a broader relaxation profile (higher FWHM and lower $\tan \delta$ peak) have a slower relaxation process, thus limiting the chain motion and shape-recovery. This trend is well-appreciated in the case of 3thiol formulations between $20 \%$ and $40 \%$ of iso, showing an increase in FWHM from 11.7 to $15.7^{\circ} \mathrm{C}$ and an increase in $t_{\mathrm{sr}}$ from 11 to $13 \mathrm{~s}$. In the case of the 4thiol formulations this trend is also observed from $30 \%$ to $40 \%$ of iso. The value of the $\tan \delta$ peak clarifies the situation when FHWM values are similar. In Figure $8 \mathrm{c}$ it is seen that $t_{\mathrm{sr}}$ decreases when the $\tan \delta$ peak increases showing a linear correlation for both the 3thiol and 4thiol systems with isocyanurate. In contrast, other network structure parameters, such as the crosslinking density given by $v_{\mathrm{e}}$ or $E_{\mathrm{r}}{ }^{\prime}$, do not have an influence on the recovery rate. As discussed in the preceding section, $v_{\mathrm{e}}$ increases with the amount of iso (see Table 2), but changes in $t_{\mathrm{sr}}$ follow the trend dictated by FWHM and $\tan \delta$ peak instead, regardless of the values of $v_{\mathrm{e}}$ or $E_{\mathrm{r}}{ }^{\prime}$. These results are in agreement with Yackaki et al. suggesting that on unconstrained experiments the main responsible of the shape-recovery process is the network relaxation process [17].
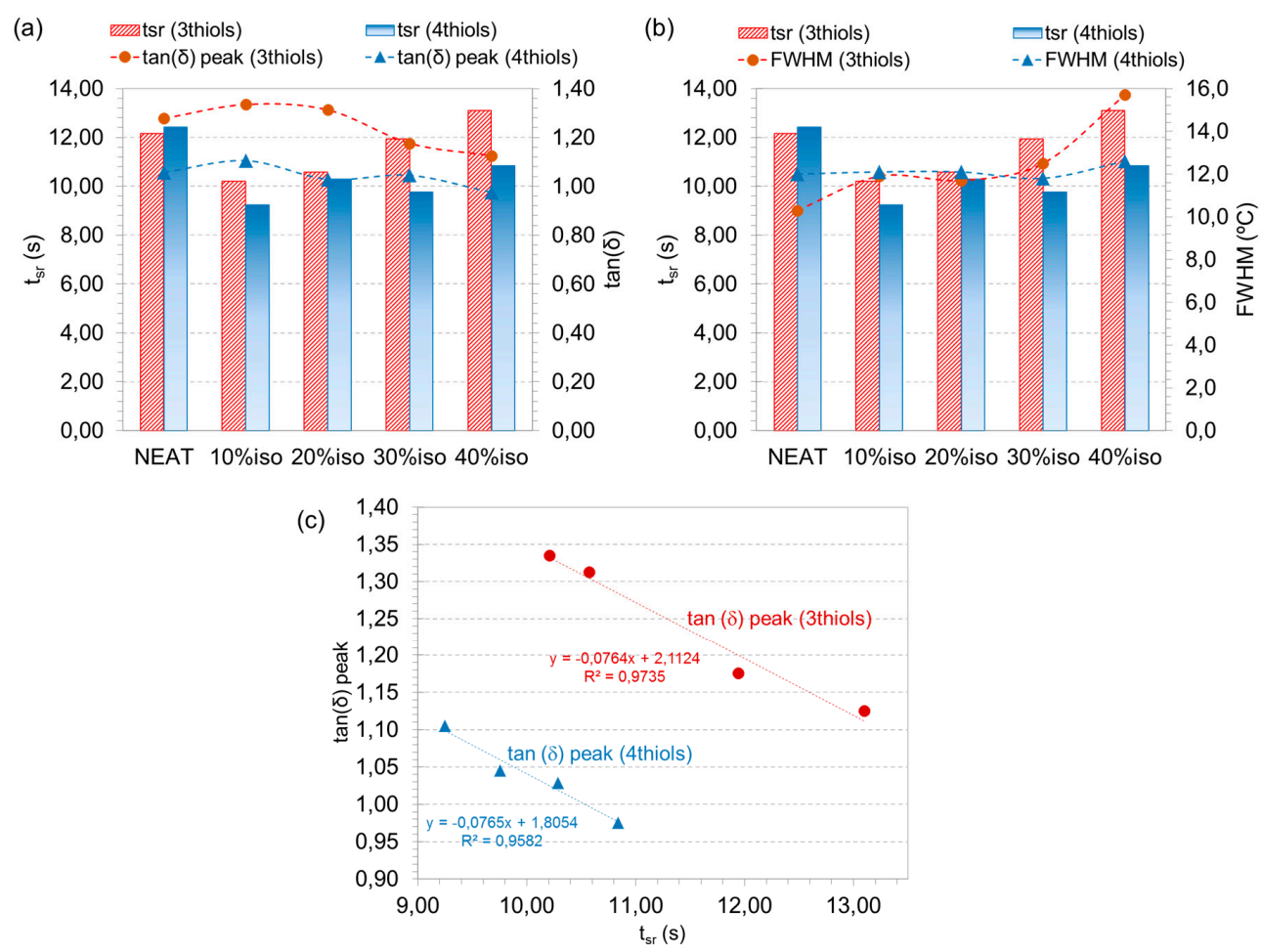

Figure 8. Relation between the shape-memory response (in terms of $t_{\mathrm{sr}}$ ) and the network relaxation dynamics; (a) $t_{\mathrm{sr}}$ against $\tan \delta$ peak as a function of the composition; (b) $t_{\mathrm{sr}}$ against FWHM as a function of the composition; (c) $\tan \delta$ peak against the $t_{\mathrm{sr}}$ for both, 3thiol and 4thiol with isocyanurate formulations $(10 \%, 20 \%, 30 \%$ and $40 \%)$.

To sum up, these results evidence the dependence of the shape-recovery with the network relaxation on unconstrained experiments and suggesting that $F W H M$ and $\tan \delta$ peak can be used to 
estimate, at least from a comparative point of view, the velocity of the shape-recovery process [39]. From the shape of the modulus curve (the steepness of the drop and the plateau zone at the glassy state), one can also obtain a qualitative view of the speed of the recovery process and the capability of the material to retain the temporary shape.

Finally, the best candidates have been chosen by applying the next criteria: the higher glass transition reached by adding the iso component to maximize temporary shape retention along with a homogeneous network structure to have fast recovery process. Therefore, the 3thiol-30\%iso and 4thiol-30\%iso formulations, along with the NEAT ones, have been chosen for further analysis in the quantitative study. While there is no doubt in the case of 4thiol formulations, the decision was more complicated in the case of the 3thiol ones. The formulations with $10 \%$ and $20 \%$ of iso are better candidates from the point of view of the recovery speed, but the formulations with $30 \%$ of iso has shown a higher $T_{\mathrm{g}}$ value and its $t_{\mathrm{sr}}$ is similar to the NEAT formulation which, overall, is excellent. In addition, as commented above, the $R_{\mathrm{r}}$ and $R_{f}$, as well as the shape-fixation were excellent for all the formulations. Therefore, for a proper comparative study, the same amount of isocyanurate should be used for both systems.

\subsection{Mechanical Analysis: Influence of the Network Structure and Programming Temperature}

One of the most important capabilities of a SMP during the programming process is the mechanical response (in terms of ultimate strain and stress), described by the $\sigma_{\mathrm{b}}$ and $\varepsilon_{\mathrm{b}}$ parameters. Figure 9 summarizes the $\sigma_{\mathrm{b}}$ and $\varepsilon_{\mathrm{b}}$ values obtained for the different formulations and the relation with the crosslinking density as a function of the $T_{\text {prog. }}$. In general, both parameters have shown a high dependence on temperature and network structure. In accordance with Rousseau and Yackaki $[9,10]$, the optimal mechanical point for all the formulations is found at the onset point $\left(T_{\mathrm{g}} E^{\prime}\right)$, where the material combines both properties: high resistance and molecular mobility, therefore leading to

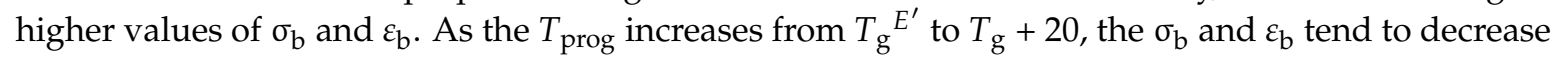
because of the material becomes weaker (i.e., for the 4thiol-NEAT system, $\sigma_{\mathrm{b}}$ and $\varepsilon_{\mathrm{b}}$ are $39 \mathrm{MPa}$ and $66 \%$ respectively, when programming at $T_{\mathrm{g}} E^{\prime}$, while programming at $T_{\mathrm{g}}$ decreases $\sigma_{b}$ and $\varepsilon_{b}$ down to $9 \mathrm{MPa}$ and $42 \%$, respectively). On the other hand, the effect of the crosslinking density of the materials on the $\sigma_{\mathrm{b}}$ and $\varepsilon_{\mathrm{b}}$ is clearly appreciated when $T_{\mathrm{prog}}$ is well above the $T_{\mathrm{g}}$. At this temperature, conformational rearrangement of network chains take place quickly in response to the stress applied, and therefore the deformation achieved $\varepsilon_{\mathrm{b}}$ is mainly limited by the crosslinking density. As can be seen, the higher the molecular weight between crosslinking points (lower $v_{\mathrm{e}}$ ), the higher the strain at break. In contrast, the trend is not well-defined for the $\sigma_{\mathrm{b}}$. The explanation must be connected with the heterogeneity of the crosslinking points and thus the differences on the physical nature of the chains created among the different formulations [8].
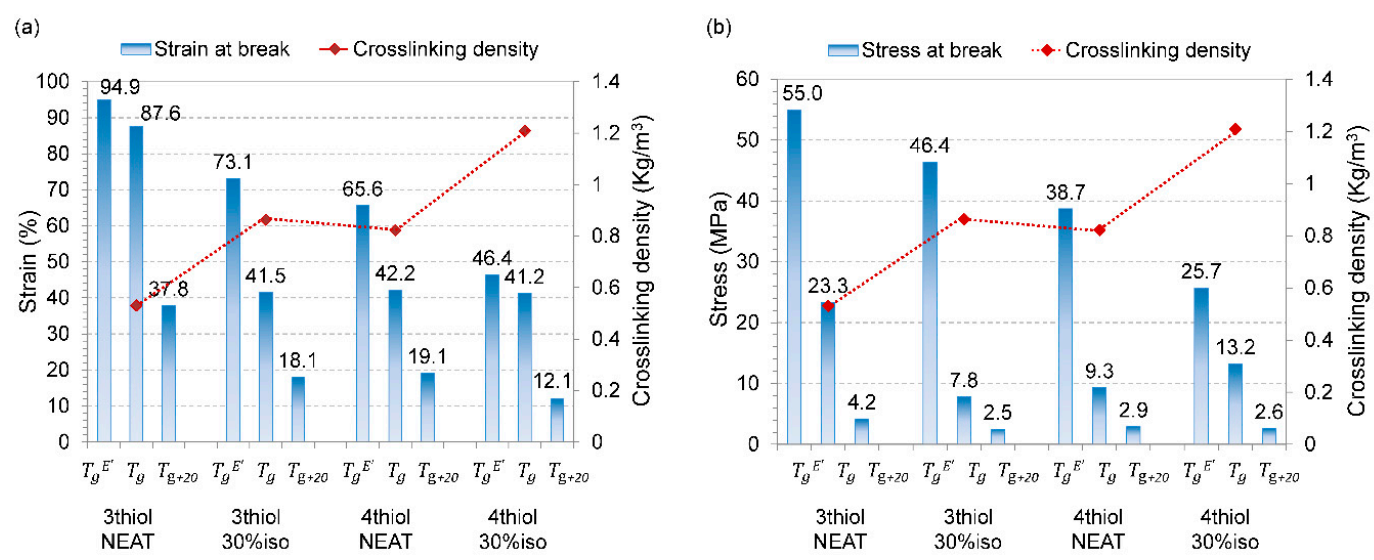

Figure 9. Mechanical response and crosslinking density as a function of the programming temperature for all the formulations of study; (a) strain at break values; (b) stress at break values. 
Overall, it should be pointed out the mechanical performance of these materials, in terms of $\sigma_{b}$ and $\varepsilon_{\mathrm{b}}$, they are superior to other epoxy-based SMPs. Williams et al. [14] reported an epoxy-amine system (based on a long aliphatic chain $n$-dodecylamine) with large tensile elongations (up to $75 \%$ ) and high recovered stresses (over $4 \mathrm{MPa}$ ), when programming at a temperature close to the $T_{\mathrm{g}}$. Rousseau et al. [10] reported epoxy-amine systems (based on long flexible polyetheramines) with higher values of $\sigma_{\mathrm{b}}$ (up to $8 \mathrm{MPa}$ ) and large ultimate strain (over $60 \%$ ), when programming at $T_{\mathrm{g}} E^{\prime}$, the optimal mechanical point. In addition, our group [15] reported epoxy-amine materials (based on polyetheramines and hyperbranched poly(ethyleneimine)s) with $\sigma_{\mathrm{b}}$ over $12 \mathrm{MPa}$ while maintaining large ultimate strain ( $\varepsilon_{\mathrm{b}}$ up to $60 \%$ ). In general terms, while the tensile elongation is enhanced by adjusting the programming temperature and the network structure, the mechanical work remains limited by the low tensile strength obtained. In the present case, the thiol-epoxy materials under study fulfil both the requirements of high tensile strain and enhanced tensile stress, thus, enhancing the energy storage capacity and therefore the expected performance on constrained experiments [40]. The 3thiol-NEAT system reaches values of almost $100 \%$ of $\varepsilon_{\mathfrak{b}}$ (comparable with those reports by the mentioned authors $[10,14,15]$ ) and $55 \mathrm{MPa}$ of $\sigma_{\mathrm{b}}$ (which is over 4 times higher than those reported by [15]) when programming at $T_{\mathrm{g}} E^{\prime}$. Furthermore, when programming at $T_{\mathrm{g}}$, the $\sigma_{\mathrm{b}}$ (over $23 \mathrm{MPa}$ ) is still higher than those reported by the mentioned authors $[10,14,15]$ and $\varepsilon_{\mathrm{b}}$ is considerably high (up to $82 \%$ ). The excellent mechanical properties found between $T_{\mathrm{g}} E^{\prime}$ and $T_{\mathrm{g}}+20$ broaden the applicability of our materials, since $T_{\text {prog }}$ not only modifies the mechanical response, but also affects the SMR [41]. In this sense, it is possible to obtain materials with specific SMR maintaining and excellent mechanical response.

\subsection{SMR Quantitative Study: Influence of the Programming Temperature}

In the quantitative study, the SMR has been investigated through the $R_{\mathrm{r}}$ and $R_{f}$ ratios (see Equations (8) and (9)). The results are represented in Figure 10.

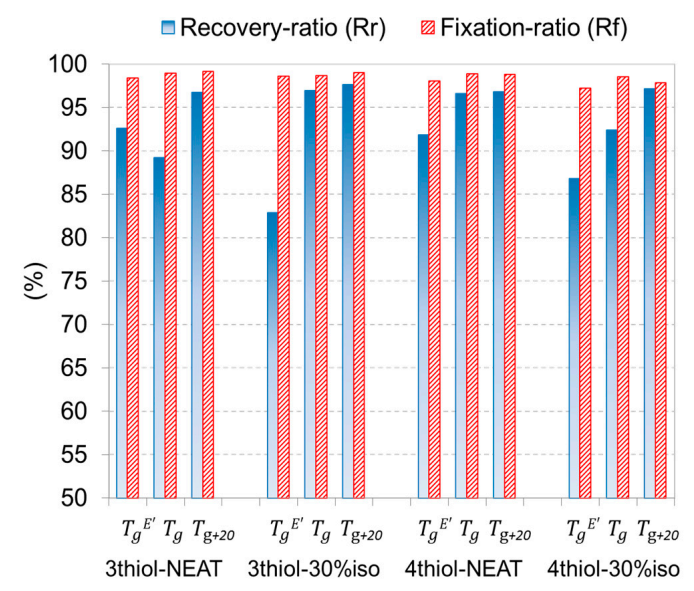

Figure 10. Recovery-ratio and fixation-ratio as a function of the programming temperature for all the formulations of study.

The capability to retain the temporary shape, quantified by the fixation-ratio, $R_{f}$, is excellent for the different materials of study with values of almost $100 \%$ regardless of the $T_{\text {prog }}$ applied. The $R_{f}$ basically depends on the mechanical response of the material during the unloading process, which occurs at $T_{\mathrm{S}}$ (the temperature at which the temporary shape is fixed). At $T_{\mathrm{s}}$ the material is in the glassy state and the modulus $\left(E_{\mathrm{g}}{ }^{\prime}\right)$ is higher than $1500 \mathrm{MPa}$ for all the formulations (see in Table 2) thus, the chain mobility is strongly hindered and the differences in the network structure do not affect the mechanical response. Accordingly, the $T_{\text {prog, }}$ which probably introduces changes in the network structure after loading and fixing the temporary shape, does not affect the $R_{f}$ for the same reason. 
In contrast, the recovery of the original shape, quantified by the recovery-ratio, $R_{\mathrm{r}}$, depends on the $T_{\text {prog: }}$ : when programming at $T_{\mathrm{g}}$ or $T_{\mathrm{g}}+20$ the values are higher (over $90 \%-96 \%$ at $T_{\mathrm{g}}$ and almost $100 \%$ at $T_{\mathrm{g}}+20$ ) than those when programming at $T_{\mathrm{g}}{ }^{\prime}$ (falling down to $83 \%$ for 3thiol-30\%iso and $87 \%$ for 4 thiol-30\%iso). Furthermore, the differences in $R_{\mathrm{r}}$ between the different formulations when they are programmed at $T_{\mathrm{g}}{ }^{\prime}$ are higher than when they are programmed at $T_{\mathrm{g}}+20$. According to Pandini et al. [41], loading at a temperature below the $T_{\mathrm{g}}$ involves more energetic changes (elastic and hardening processes) while loading at a temperature above the $T_{\mathrm{g}}$ involves mostly entropic changes. The energy lost during the loading process is higher when the loading involves more energetic molecular changes (at $T_{\mathrm{g}} E^{\prime}$ ) [42] because of molecular friction. The low initial chain mobility and the activation of the chain relaxation during programming at this temperature, result in some inter-molecular flow friction. Part of the deformation work corresponds to viscous flow and cannot be recovered, therefore the energy available for the recovery process is not enough to lead it to completion, resulting in a decrease in $R_{\mathrm{r}}$. In addition, depending on the nature of the chains (molecular structure), the energy lost during the loading process at $T_{\mathrm{g}}{ }^{\prime}$ is different. In the case of the NEAT formulations, the $R_{\mathrm{r}}$ is higher and similar for both systems, 3thiol and 4thiol, while adding the isocyanurate decreases the $R_{\mathrm{r}}$ in both systems probably due to the increase in the rigidity of the chains. Moreover, the 3 thiol-30\%iso shows a lower value of $R_{\mathrm{r}}$ than the 4 thiol-30\%iso. This must be connected with the previous results of the thermo-mechanical characterization of the materials. Both the presence of the side ethyl chain in the structure of 3thiol and some reactivity and compatibility issues, resulting in a distortion of the network structure and mobility and a broadening of the relaxation, may explain the higher energy losses in the 3 thiol formulation with $30 \%$ iso. These results suggests that by properly varying the $T_{\text {prog }}$ a balance enhancing both, the mechanical response and the shape-recovery capability is possible.

In Figure 11, the shape-recovery process is analyzed by means of $V_{\mathrm{r}}$ (through 3 consecutive cycles), enclosing the whole process (from $1 \%$ to $100 \%$ of the original shape recovered), or avoiding the early and final stages (from $15 \%$ to $85 \%$ ). In general, as it was expected from the results of the qualitative study, all the formulations have shown very high values. If one focuses on the middle stage $(15 \%-85 \%)$, the values range from $6.3 \% /{ }^{\circ} \mathrm{C}$ to $8 \% /{ }^{\circ} \mathrm{C}$ which are comparable with those reported by [15], thus, allowing almost fully recover of the original shape in very few minutes. On the other hand, using the average $(1 \%-100 \%)$, the effect of both the early and final stages is incorporated. As it can be seen, the time needed to fully recover the original shape is 2 or 3 times higher. These results evidence that the shape-recovery process is limited by the early and final stages and therefore the control of these stages is crucial to adjust the shape-recovery process as desired.

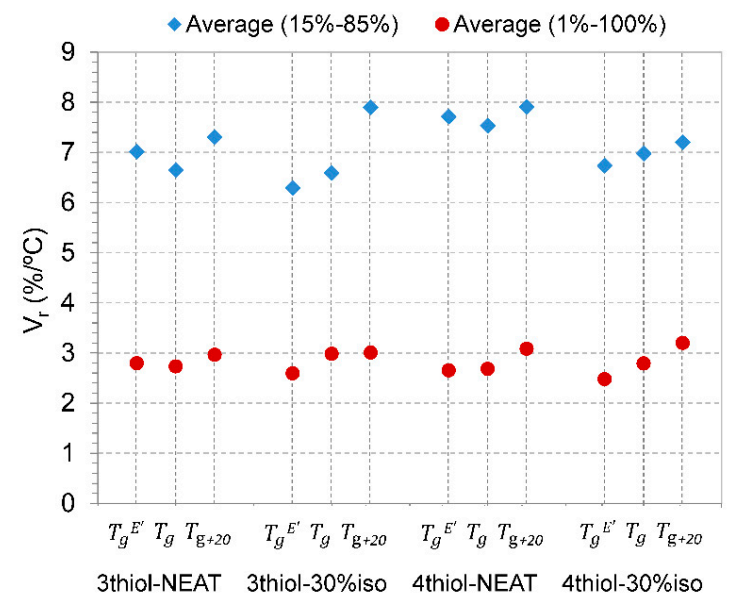

Figure 11. Shape-recovery rate $\left(\% /{ }^{\circ} \mathrm{C}\right)$, enclosing the whole shape-recovery process $(1 \%-100 \%)$ and avoiding the early and final stages $(15 \%-85 \%)$, as a function of the programming temperature for all the formulations of study. 
On analyzing the effect of the programming temperature with the $V_{\mathrm{r}}$, it is seen an increment of the $V_{\mathrm{r}}$ with the temperature. This phenomenon is well appreciated if one encloses the whole process $\left(1 \%-100 \%\right.$ ) (i.e., the 4 thiol-30\%iso increases the $V_{\mathrm{r}}$ from $2.5 \% /{ }^{\circ} \mathrm{C}$ up to $3.2 \% /{ }^{\circ} \mathrm{C}$ and the 3 thiol-30\%iso from $2.6 \% /{ }^{\circ} \mathrm{C}$ up to $3.0 \% /{ }^{\circ} \mathrm{C}$ )., This is probably connected with the lower rate of recovery $R_{\mathrm{r}}$ when programming at $T_{\mathrm{g}}{ }^{E}$ (see Figure 10). Following the same line of reasoning as above, the lower amount of energy that is effectively stored and available for the recovery process (due to molecular friction losses) decreases both the recovery ratio $R_{\mathrm{r}}$ and the $V_{\mathrm{r}}$, thus increasing the time needed to fully recover the original shape. It may be speculated that the resulting stretched network structure of the temporary shape is somewhat altered when programming at $T_{\mathrm{g}}{ }^{E}$ and this may also have an effect on the recovery rate. Whatever the specific cause, this is of particular importance in the case of the 3 thiol-30\%iso, being the effect of the programming temperature very strong in the central part of the process $(15 \%-85 \%)$, and this may be connected with the lowering and broadening of the relaxation described above for the 3thiol-30\% (see Table 2 and Figure 8).

In spite of the differences in the relaxation process of the different formulations described in the previous sections, the average recovery speed is similar among the different formulations, especially if one encloses the whole process $(1 \%$ to $100 \%)$. The overall trends with respect to the network structure and the shape of the relaxation process are not as clearly defined as in the qualitative study and depend also on the programming temperature. The recovery process in the qualitative study was analyzed under isothermal conditions, using a fixed programming and recovery temperature relative to the network relaxation determined by DMA. Therefore, the time/velocity effect, which is connected with the relaxation dynamics, could be analyzed independently. In contrast, the shape-recovery takes place with increasing temperature in the quantitative study. In this case, there is a time-temperature coupling that adds complexity to the process and makes it more difficult to interpret the average recovery speed data, especially taking into account that there are small differences in terms of relaxation shape but clearly different relaxation temperatures. However, it has been observed that during the recovery process there is indeed a strong effect of the network relaxation dynamics, especially when temperature is still below $T_{\mathrm{g}}$. There is an excellent correspondence between the early stage of the recovery process and the early stage of the relaxation process determined from the DMA experiments (data not shown). Afterwards, at some point, the temperature enhances the molecular mobility and the recovery process is able to proceed more freely causing acceleration and minimizing the effect of the network structure. Therefore, enclosing the whole process, the effect of the relaxation process is clearly minimized, while focusing on the central part $(15 \%-85 \%)$ this effect on the early stage has a major role. To this end, by properly tailoring the network structure and programming temperature, the effect at the early stage of the shape-recovery process can be tuned as desired, obtaining higher or lower rates which at the end of the process will be adjusted.

In conclusion, these results evidence the possibility to tailor the early stage and eventually the whole shape-recovery process by properly modifying the network structure and its relaxation dynamics, and the programming temperature. Moreover, the effect on the mechanical properties (stress and strain at break) is also investigated, thus, making possible a balance between mechanical performance and shape-memory performance.

\section{Conclusions}

Materials based on epoxy-thiol "click" chemistry have been obtained, with enhanced mechanical properties and well-defined network structures. The different materials have been characterized by dynamic-mechanical analysis and been tested as SMPs from a qualitative and quantitative point of view. The effect of the material network structure and the programming temperature $T_{\text {prog }}$ on the SMR in unconstrained shape-recovery scenarios has been discussed and analyzed in detail.

It has been seen that the network structure of epoxy-thiol materials can be finely tuned by changing both the thiol crosslinker functionality and by introducing a rigid trifunctional epoxy resin. 
In general, a good agreement between the experimental data and the expected network structure has been obtained. From the results of the dynamic-mechanical analysis and a qualitative visual methodology for the analysis of the SMR it has been found that the shape-recovery process is highly dependent on the network relaxation dynamics. Thus, the sharpness in the relaxation peak $\tan \delta$ or the shape of the drop in elastic modulus, can be used to predict, at least from a comparative point of view, the shape-memory response of the materials.

Prior to the quantitative analysis, the stress and strain at break values have been determined for a range of temperatures and an optimal point has been found at the onset point of the relaxation process. Values of stress and strain that break as high as $100 \%$ and $55 \mathrm{MPa}$, respectively, have been reached. A strong dependence of the crosslinking density with the strain at break at $T_{\mathrm{g}}+20$ has been found, when the network structure rapidly reaches a relaxed state while the deformation is occurring. As the crosslinking density increases, the strain at break decreases.

From the quantitative analysis, it has been seen that some parameters such as the ratio of fixation are not affected by programming conditions or network structure, reaching values around $100 \%$. In contrast, the recovery ratio has a strong dependence on both the programming temperature and the network structure: the energy lost during the loading process is significantly reduced due to the decrease in chain friction produced by the network relaxation as the programming temperature is increased. At lower temperatures $\left(T_{\mathrm{g}} E^{\prime}\right)$, the amount of energy lost during the loading process is strongly related to the network structure. Following the same reasoning as above, the shape-recovery rate of the shape-recovery process increases by the reduction of energy lost during the loading process on increasing programming temperature. There is a complex time-temperature superposition during the recovery process with increasing temperature, but it has been found a close relationship between the relaxation process determined with DMA and the measured shape recovery process.

In conclusion, the network structure properties give us an idea of the expected shape-fixation and retention of the temporary shape during the fixation and storage processes, while the network relaxation process is a powerful tool to define the shape-recovery process on unconstrained experiments. In addition, the $T_{\text {prog }}$ has an important impact on the SMR, being a crucial parameter during loading stage and the shape-recovery process: not only the $\sigma_{\mathrm{b}}$ and $\varepsilon_{\mathrm{b}}$ can be adjusted by varying the $T_{\text {prog, }}$, but also the shape-recovery process (enclosing the whole-process path) can be tuned as desired.

Acknowledgments: The authors would like to thank MICINN (MAT2014-53706-C03-01) and Generalitat de Catalunya (2014-SGR-67) for its financial support.

Author Contributions: Xavier Fernández-Francos and Silvia De la Flor conceived and designed the experiments, which were performed and analyzed by Alberto Belmonte. Dailyn Guzmán contributed on the samples preparation and characterization. Alberto Belmonte wrote the paper. Silvia De la Flor and Xavier Fernández-Francos revised the paper.

Conflicts of Interest: The authors declare no conflict of interest.

\section{References}

1. Lendlein, A.; Sauter, T. Shape-memory effect in polymers. Macromol. Chem. Phys. 2013, 214, 1175-1177. [CrossRef]

2. Julich-Gruner, K.K.; Löwenberg, C.; Neffe, A.T.; Behl, M.; Lendlein, A. Recent trends in the chemistry of shape-memory polymers. Macromol. Chem. Phys. 2013, 214, 527-536. [CrossRef]

3. Santhosh Kumar, K.S.; Biju, R.; Reghunadhan Nair, C.P. Progress in shape memory epoxy resins. React. Funct. Polym. 2013, 73, 421-430. [CrossRef]

4. Mather, P.T.; Luo, X.; Rousseau, I.A. Shape memory polymer research. Annu. Rev. Mater. Res. 2009, 39, 445-471. [CrossRef]

5. Sun, L.; Huang, W.M.; Ding, Z.; Zhao, Y.; Wang, C.C.; Purnawali, H.; Tang, C. Stimulus-responsive shape memory materials: A review. Mater. Des. 2012, 33, 577-640. [CrossRef] 
6. Rousseau, I.A.; Xie, T. Shape memory epoxy: Composition, structure, properties and shape memory performances. J. Mater. Chem. 2010, 20, 3431-3441. [CrossRef]

7. Wei, K.; Zhu, G.; Tang, Y.; Niu, L. Shape-memory effects of a hydro-epoxy resin system. J. Polym. Res. 2013, 20, 123. [CrossRef]

8. Feldkamp, D.M.; Rousseau, I.A. Effect of chemical composition on the deformability of shape-memory epoxies. Macromol. Mater. Eng. 2011, 296, 1128-1141. [CrossRef]

9. Yakacki, C.M.; Willis, S.; Luders, C.; Gall, K. Deformation limits in shape-memory polymers. Adv. Eng. Mater. 2008, 10, 112-119. [CrossRef]

10. Feldkamp, D.M.; Rousseau, I.A. Effect of the deformation temperature on the shape-memory behavior of epoxy networks. Macromol. Mater. Eng. 2010, 295, 726-734. [CrossRef]

11. Zheng, N.; Fang, G.; Cao, Z.; Zhao, Q.; Xie, T. High strain epoxy shape memory polymer. Polym. Chem. 2015, 6, 3046-3053. [CrossRef]

12. Arrieta, S.; Diani, J.; Gilormini, P. Experimental characterization and thermoviscoelastic modeling of strain and stress recoveries of an amorphous polymer network. Mech. Mater. 2014, 68, 95-103. [CrossRef]

13. Arrieta, J.S.; Diani, J.; Gilormini, P. Cyclic and monotonic testing of free and constrained recovery properties of a chemically crosslinked acrylate. J. Appl. Polym. Sci. 2014. [CrossRef]

14. Leonardi, A.B.; Fasce, L.A.; Zucchi, I.A.; Hoppe, C.E.; Soulé, E.R.; Pérez, C.J.; Williams, R.J.J. Shape memory epoxies based on networks with chemical and physical crosslinks. Eur. Polym. J. 2011, 47, 362-369. [CrossRef]

15. Santiago, D.; Fernández-Francos, X.; Ferrando, F.; de la Flor, S. Shape-memory effect in hyperbranched poly(ethyleneimine)-modified epoxy thermosets. J. Polym. Sci. Polym. Phys. 2015, 924-933. [CrossRef]

16. Yakacki, C.M.; Shandas, R.; Lanning, C.; Rech, B.; Eckstein, A.; Gall, K. Unconstrained recovery characterization of shape-memory polymer networks for cardiovascular applications. Biomaterials 2007, 28, 2255-2263. [CrossRef] [PubMed]

17. Yakacki, C.M.; Shandas, R.; Safranski, D.; Ortega, A.M.; Sassaman, K.; Gall, K. Strong, tailored, biocompatible shape-memory polymer networks. Adv. Funct. Mater. 2008, 18, 2428-2435. [CrossRef] [PubMed]

18. Chen, X.; Nguyen, T.D. Influence of thermoviscoelastic properties and loading conditions on the recovery performance of shape memory polymers. Mech. Mater. 2011, 43, 127-138. [CrossRef]

19. Binder, W.H.; Sachsenhofer, R. "Click" chemistry in polymer and materials science. Macromol. Rapid Commun. 2007, 28, 15-54. [CrossRef]

20. Moses, J.E.; Moorhouse, A.D. The growing applications of click chemistry. Chem. Soc. Rev. 2007, 36, 1249-1262. [CrossRef] [PubMed]

21. Kolb, H.C.; Finn, M.G.; Sharpless, K.B. Click chemistry: Diverse chemical function from a few good reactions. Angew. Chem. Int. Ed. Engl. 2001, 40, 2004-2021. [CrossRef]

22. Brändle, A.; Khan, A. Thiol-epoxy "click" polymerization: Efficient construction of reactive and functional polymers. Polym. Chem. 2012, 3, 3224-3227. [CrossRef]

23. Flores, M.; Tomuta, A.M.; Fernández-Francos, X.; Ramis, X.; Sangermano, M.; Serra, A. A new two-stage curing system: Thiol-ene/epoxy homopolymerization using an allyl terminated hyperbranched polyester as reactive modifier. Polymer 2013, 54, 5473-5481. [CrossRef]

24. Carlborg, C.F.; Vastesson, A.; Liu, Y.; van der Wijngaart, W.; Johansson, M.; Haraldsson, T. Functional off-stoichiometry thiol-ene-epoxy thermosets featuring temporally controlled curing stages via an UV/UV dual cure process. J. Polym. Sci. Polym. Chem. 2014, 52, 2604-2615. [CrossRef]

25. Guzmán, D.; Ramis, X.; Fernández-Francos, X.; Serra, A. New catalysts for diglycidyl ether of bisphenol A curing based on thiol-epoxy click reaction. Eur. Polym. J. 2014, 59, 377-386. [CrossRef]

26. Guzmán, D.; Ramis, X.; Fernández-Francos, X.; Serra, A. Enhancement in the glass transition temperature in latent thiol-epoxy click cured thermosets. Polymers 2015, 7, 680-694. [CrossRef]

27. Nair, D.P.; Cramer, N.B.; Scott, T.F.; Bowman, C.N.; Shandas, R. Photopolymerized thiol-ene systems as shape memory polymers. Polymer 2010, 51, 4383-4389. [CrossRef] [PubMed]

28. Sunitha, K.; Santhosh Kumar, K.S.; Mathew, D.; Reghunadhan Nair, C.P. Shape memory polymers (SMPs) derived from phenolic cross-linked epoxy resin via click chemistry. Mater. Lett. 2013, 99, 101-104. [CrossRef] 
29. McBride, M.K.; Gong, T.; Nair, D.P.; Bowman, C.N. Photo-mediated copper(I)-catalyzed azide-alkyne cycloaddition (CuAAC) "click" reactions for forming polymer networks as shape memory materials. Polymer 2014, 55, 5880-5884. [CrossRef] [PubMed]

30. Graessley, W.W. Statistical mechanics of random coil networks. Rubber Chem. Technol. 1975, 48, $1008-1017$. [CrossRef]

31. Miller, D.R.; Macosko, C.W. A new derivation of postgel properties of network polymers. Rubber Chem. Technol. 1976, 49, 1219-1231. [CrossRef]

32. Charlesworth, J.M. Effect of crosslink density on molecular relaxations in diepoxide-diamine network polymers. Part 2. The rubbery plateau region. Polym. Eng. Sci. 1988, 28, 230-236. [CrossRef]

33. Lesser, A.; Crawford, E. The role of network architecture on the glass transition temperature of epoxy resins. J. Appl. Polym. Sci. 1997, 66, 387-395. [CrossRef]

34. Pascault, J.-P.; Sautereau, H.; Verdu, J.; Williams, R.J.J. Thermosetting Polymers; CRC Press: New York, NY, USA, 2002.

35. Charlesworth, J.M. The glass transition temperature for non-gaussian network polymers. J. Macromol. Sci. 1987, 26, 105-133. [CrossRef]

36. Hale, A.; Macosko, C.W.; Bair, H.E. Glass transition temperature as a function of conversion in thermosetting polymers. Macromolecules 1991, 24, 2610-2621. [CrossRef]

37. Liu, Y.; Han, C.; Tan, H.; Du, X. Thermal, mechanical and shape memory properties of shape memory epoxy resin. Mater. Sci. Eng. A 2010, 527, 2510-2514. [CrossRef]

38. Fan, M.; Yu, H.; Li, X.; Cheng, J.; Zhang, J. Thermomechanical and shape-memory properties of epoxy-based shape-memory polymer using diglycidyl ether of ethoxylated bisphenol-A. Smart Mater. Struct. 2013. [CrossRef]

39. Rousseau, I.A.; Xie, T. Relationship between materials properties and shape memory behavior in epoxy-amine polymers. MRS Proc. 2009, 1190, 31-36. [CrossRef]

40. Anthamatten, M.; Roddecha, S.; Li, J. Energy storage capacity of shape-memory polymers. Macromolecules 2013, 46, 4230-4234. [CrossRef]

41. Pandini, S.; Bignotti, F.; Baldi, F.; Passera, S. Network architecture and shape memory behavior of cold-worked epoxies. J. Intell. Mater. Syst. Struct. 2013, 24, 1583-1597. [CrossRef]

42. Gu, Y.; Li, S.X. Thermo-mechanical behavior of epoxy shape memory polymer. Adv. Mater. Res. 2013, 721, 169-172. [CrossRef]

(C) 2015 by the authors; licensee MDPI, Basel, Switzerland. This article is an open access article distributed under the terms and conditions of the Creative Commons by Attribution (CC-BY) license (http:/ / creativecommons.org/licenses/by/4.0/). 